\title{
Comparative study of osteoarthritis induced by monoiodoacetate and papain in rabbit temporomandibular joints: macroscopic and microscopic analysis
}

\author{
M. Molinet ${ }^{1,2 *}$, N. Alves ${ }^{2,3,4 *}$, A. Vasconcelos ${ }^{5}$, N.F. Deana ${ }^{6}$ \\ 'Escuela de Tecnología Médica, Universidad Austral de Chile, Sede Puerto Montt, Chile \\ ${ }^{2}$ Master Programme in Sciences, Mention Morphology, Faculty of Medicine, Universidad de La Frontera, Temuco, Chile \\ ${ }^{3}$ Applied Morphology Research Centre (CIMA), Faculty of Dentistry, Temuco, Chile \\ ${ }^{4}$ Centre of Excellence in Surgical and Morphological Research (CEMyQ), Faculty of Medicine, Temuco, Chile \\ ${ }^{5}$ Department of Basic Sciences, Faculty of Medicine, Chile \\ ${ }^{6}$ Centre for Research in Epidemiology, Economics and Oral Public Health (CIEESPO), Faculty of Dentistry, \\ Universidad de La Frontera, Temuco, Chile
}

[Received: 10 May 2019; Accepted: 17 June 2019]

Background: Osteoarthritis (OA) is a chronic, progressive, degenerative pathology. Inducing $O A$ in an animal model is useful for studying the pathology and testing the effectiveness of new treatments. The object of the present study was to determine the macroscopic and microscopic changes occurring in rabbit temporomandibular joints (TMJ) at 15, 30 and 45 days after induction of OA by monoiodoacetate (MIA) and papain.

Materials and methods: Twenty two male rabbits were used in the experiment, divided into three groups: a control group $(n=4)$ and two experimental groups, MIA $(n=9)$ and papain $(n=9)$. The progress of the disease was analysed at 15, 30 and 45 days after induction of OA. Morphological and histological analyses were carried out of the joint disc and the mandibular condyle.

Results: The most evident changes were expressed in the condyle and disc of joints with OA induced by MIA. The condyles presented deformation, fissures and loss of joint surface, the chondrocytes lost their morphology and organisation. In more advanced stages there was loss of the mid zone of the joint disc.

Conclusions: The effects of papain were associated with condyle deformation, disorientation of the chondrocytes in the middle layer, and proliferation in deep zones; there was also an increase in the extracellular matrix. Both inductors generated changes in the TMJ and its joint surfaces; MIA was more effective and coincided more closely with the classic signs of the evolution of OA. (Folia Morphol 2020; 79, 3: 516-527)

Key words: osteoarthrosis, temporomandibular joint, monoidoacetate, papain, rabbit 


\section{INTRODUCTION}

Osteoarthritis (OA) is defined as a chronic, progressive degenerative pathology, characterised by cartilage degradation, remodelling of the subchondral bone, synovitis, narrowing of the joint space, formation of osteophytes and chronic pain [24]. The repair process after cartilage damage involves inflammation, cell proliferation and synthesis of elastic, collagen and reticular fibres [11]. In the temporomandibular joint (TMJ), the most common signs and symptoms are swelling, palpable sensitivity to pain, crepitation, limited mandibular movement and functional impotence [5].

Pre-clinical studies to induce $O A$ in the TMJ facilitate description of the physiopathology of the disease, and are fundamental for testing new anti-rheumatic drugs or other types of therapy in order to evaluate the effectiveness of new techniques and the possible adverse effects of such treatments. OA can be induced surgically; this method produces good results in terms of degeneration and anterior displacement of the joint disc; however, it may also determine damage to adjacent structures [22]. A mechanical model can also be used to induce $O A$, by impact, immobilisation and repetitive load [13]. Finally, OA can be induced chemically using carrageenan [21], interleukin-1 [18], Freund's adjuvant [9], monoidoacetate [4] and enzymes such as papain [7] and collagenase [13]. The advantage of chemical induction of OA is that the concentration of the substances can be controlled, modulating the progression and gravity of the lesions [7]. Furthermore, chemical induction causes less suffering to the animal, which is not subject to the risks involved in surgery. OA induction by intra-articular injection is a quick, efficient method of producing the pathology in the joint components $[14,20,24]$, with symptoms such as thickening of the articular capsule, diminution in the trabecular bone volume of the subchondral bone [7], exposure of the subchondral bone, diminution of the thickness and cellularity of the joint disc [4]. OA induction by monoidoacetate (MIA) reproduces cartilage lesions and functional deterioration of the joint, similar to $O A$ in humans, by causing chondrocyte death [4]. OA induction by papain affects the components of the extracellular matrix of the joint, imitating the primary changes observed in the disease $[4,8]$. In a previous work we observed by cone-beam computed tomography that both inductors (papain and MIA) were able to generate changes in the TMJ of rabbits compatible with OA [1]. Both inductors offer the great advantage of allowing the progression and severity of the joint lesions to be modulated easily [24]; however, there is no comparison in the literature of their effectiveness in generating OA. The object of this work was therefore to compare the effectiveness of these two chemical inductors (papain and MIA) in generating morphological changes compatible with OA in rabbit TMJs.

\section{MATERIALS AND METHODS}

This study was carried out in accordance with the Ethical Principles and Guidelines for Experiments on Animals and with the Chilean regulations on the practical, educational and scientific use of vivisection. The study was approved by the Scientific Ethics Committee of Universidad de La Frontera, folio no. 088/14.

\section{Sample}

Twenty-two young adult male rabbits, age 5 months, weight between 3 and $4 \mathrm{~kg}$, of the New Zealand breed (Oryctolagus cuniculus L.) were used in the experiments. The animals were kept in individual cages, to which they were assigned at random. All the rabbits were kept under the same environmental conditions, with food ad libitum consisting of rabbit feed, greens and water, in the bioterium of the Centre of Excellence in Morphological and Surgical Studies (CEMyQ). The habitat was kept under appropriate light cycle, temperature and moisture. The rabbits were identified by marking their ears with indelible ink, and an identifying plate was affixed to each cage. They were monitored throughout the study by a veterinary doctor, controlling their pain and their intake of water and food.

\section{Osteoarthritis induction}

The rabbits were divided at random into three groups:

- one experimental group with $\mathrm{OA}$ induction by MIA $(\mathrm{n}=9)$;

- one experimental group with OA induction by papain $(\mathrm{n}=9)$;

- one control group which did not suffer OA induction $(n=4)$ (Fig. 1). 


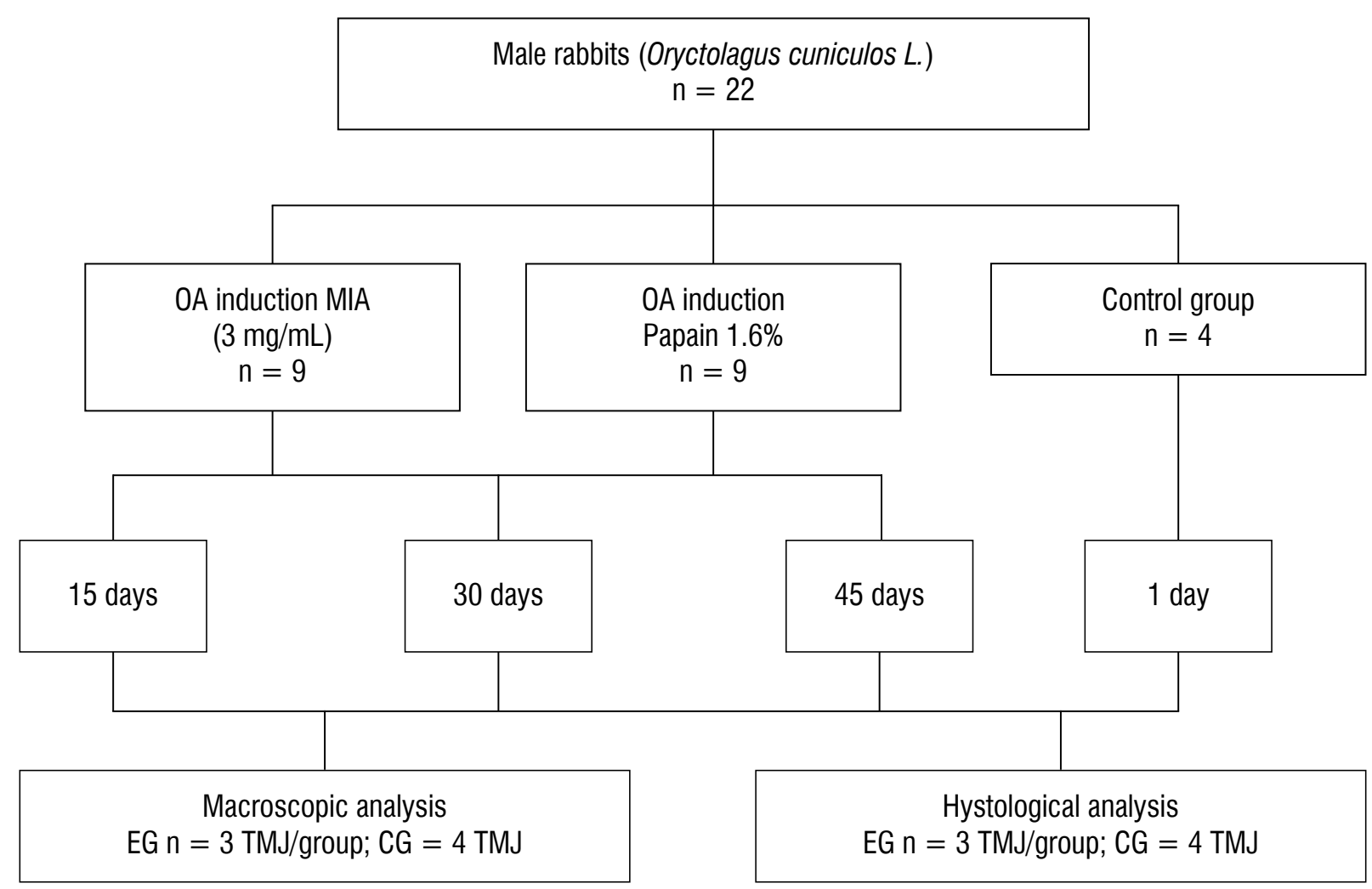

Figure 1. Flow-chart showing the assignment of animals to the control group (CG) or experimental group (EG), and analysis of the results; MIA — monoiodoacetate; $\mathrm{OA}$ — osteoarthritis; TMJ — temporomandibular joints.

The rabbits in the experimental groups were anaesthetised by intramuscular injection of ketamine $5 \%(20 \mathrm{mg} / \mathrm{kg})$ and xylazine $(0.1 \mathrm{mg} / \mathrm{kg})$. OA induction was carried out by arthrocentesis in the lower compartment of the articular cavity of both TMJs of the rabbits in both experimental groups. OA was induced in the first experimental group by intra-articular injection of $3 \mathrm{mg}$ of MIA dissolved in $50 \mu \mathrm{L}$ of sterile saline solution in a single dose [7]. The reference point used for the injection was the posterior margin of the rabbit's eye; the zygomatic arch was penetrated deeply, $8 \mathrm{~mm}$ posterior of the reference point, with a $25 \mathrm{G} 5 / 8$ hypodermic needle. The skin was shaved prior to perforation and the needle was inserted at an inclination of $45-55^{\circ}$ above horizontal in order to ensure entry into the articular cavity. All the solution was immediately injected slowly. The same arthrocentesis technique was used to induce $O A$ in the second experimental group [16]. The papain was administered together with L-cysteine activator, in three doses of $0.1 \mathrm{~mL}$ of solution $1.6 \%$ on days 1 , 4 and $7[14,20]$.

\section{Euthanasia and dissection}

The rabbits were randomised again and 3 animals from each experimental group were specified on days 15,30 and 45 after OA induction. Euthanasia was carried out by administering ketamine ( $35 \mathrm{mg} / \mathrm{kg}$ ) and xylazine ( $5 \mathrm{mg} / \mathrm{kg}$ ) by intramuscular injection. The animal was observed to enter deep anaesthesia (verified by eyeball inspection), and then a double dose of anaesthetic was administered.

The region of the mandibular ramus was shaved and an incision was made with a scalpel. The masseter and temporalis muscles were displaced sequentially to expose the joint capsule. The TMJ was then removed en bloque using a hand saw.

\section{Morphometric analysis}

The right TMJ of each rabbit was used for morphometric analysis. The structures were separated to measure the mandibular condyle (height and transverse diameter), joint disc (thickness of the anterior zone, thickness of the posterior zone, and 
Table 1. A cartilage histopathology severity assessment methodology, following Pritzker et al. [19]

\begin{tabular}{|c|c|c|}
\hline $\begin{array}{l}\text { Degree of } \\
\text { severity }\end{array}$ & Description & Associated criteria (tissue reaction) \\
\hline \multirow[t]{2}{*}{0} & \multirow{2}{*}{$\begin{array}{l}\text { Surface intact, } \\
\text { cartilage morphology intact }\end{array}$} & Matrix: normal architecture \\
\hline & & Cells: intact, appropriate orientation \\
\hline \multirow[t]{3}{*}{1} & \multirow[t]{3}{*}{ Surface intact } & $\begin{array}{l}\text { Matrix: superficial zone intact, oedema and/or superficial fibrillation (abrasion), } \\
\text { focal superficial matrix condensation }\end{array}$ \\
\hline & & Cells: death, proliferation (clusters), hypertrophy, superficial zone \\
\hline & & Reaction must be more than superficial fibrillation only \\
\hline \multirow[t]{5}{*}{2} & \multirow[t]{5}{*}{ Surface discontinuity } & As above \\
\hline & & + Matrix discontinuity at superficial zone (deep fibrillation) \\
\hline & & \pm Cationic stain matrix depletion upper $1 / 3$ cartilage \\
\hline & & \pm Disorientation of chondron columns \\
\hline & & Cells; death, proliferation (clusters), hypertrophy \\
\hline \multirow[t]{5}{*}{3} & \multirow[t]{5}{*}{ Vertical fissures (clefts) } & As above \\
\hline & & Matrix vertical fissures into mid zone branched fissures \\
\hline & & \pm Cationic stain depletion into lower $2 / 3$ of cartilage (deep zone) \\
\hline & & \pm New collagen formation \\
\hline & & Cells: death, regeneration (clusters), hypertrophy, cartilage areas adjacent to fissures \\
\hline \multirow[t]{2}{*}{4} & \multirow[t]{2}{*}{ Erosion } & Cartilage matrix loss: delamination of superficial layer, mid layer cyst formation \\
\hline & & Excavation: matrix loss in superficial layer and mid layer \\
\hline 5 & Denudation & $\begin{array}{l}\text { Surface: sclerotic bone or repair tissue including fibrocartilage within denuded surface. } \\
\text { Microfracture with repair limited to bone surface }\end{array}$ \\
\hline 6 & Deformation & $\begin{array}{l}\text { Bone remodelling (more than osteophyte formation only). Includes: microfracture with } \\
\text { fibrocartilaginous and osseous repair extending above the previous surface }\end{array}$ \\
\hline
\end{tabular}

height) and the articular tubercle (anteroposterior diameter and depth). The measurements were taken in $\mathrm{mm}$ with a digital calliper (accuracy $0.01 \mathrm{~mm}$ ).

\section{Histological analysis}

The histological analysis was carried out with the TMJ en bloque, fixed with formalin $10 \%$ for conservation purposes. The samples were decalcified with Ana Morse solution, dehydrated and clarified. They were then embedded in paraffin blocks and cut into $5 \mu \mathrm{m}$ sections. The plates obtained were deparaffinized and rehydrated, and finally routine staining was carried out with haematoxylin and eosin. The plates were observed under an Axio Scope A1 microscope, Zeiss, Germany, and photographed with an AxioCamICc5 camera at $10 \times$ and $40 \times$ magnification.

\section{Qualitative analysis of the severity of osteoarthritis}

The qualitative histological evaluation of the changes produced on the joint surfaces was based on the criteria of the Osteoarthritis Research Society International (OARSI), as described by Pritzker et al. [19]. In Pritzker et al.'s classification [19], normal cartilage is classified as 0 and severity is classified in 6 different categories, 1-4 for articular changes and 5-6 for damage to the subchondral bone (Table 1). The degree of severity (DS) was analysed by two blinded evaluators (M.M. and A.V.). The images were first coded and then randomised by computer. In cases of doubt or disagreement between the evaluations a third researcher was consulted (N.A.) to obtain consensus in the evaluation. 
Table 2. Comparison of mean values for the mandibular condyle between the control group and the experimental groups (MIA and papain) against time $(15,30$ and 45 days)

\begin{tabular}{lcccc}
\hline Groups & & Mandibular condyle & \\
\cline { 3 - 5 } & & High & Transverse diameter \\
Mean (SD) & $\begin{array}{c}\text { Anteroposterior diameter } \\
\text { Mean (SD) }\end{array}$ \\
\hline Control group & & $4.64(0.41)$ & $3.44(0.57)$ \\
15 days & MIA & $5.98(0.91)$ & $5.00(0.64)$ & $3.31(0.45)$ \\
& Papain & $5.84(0.83)$ & $5.09(0.08)$ & $3.25(0.56)$ \\
& P & 0.497 & 0.265 & 0.716 \\
30 days & MIA & $5.05(0.47)$ & $4.75(0.44)$ & $2.89(0.38)$ \\
& Papain & $5.17(1.28)$ & $4.59(0.39)$ & $2.85(0.28)$ \\
& P & 0.955 & 0.881 & 0.368 \\
45 days & MIA & $7.13(1.61)$ & $4.76(0.35)$ & $4.24(0.70)$ \\
& Papain & $5.78(1.27)$ & $5.06(0.54)$ & $3.03(0.32)$ \\
& P & 0.165 & 0.764 & 0.101 \\
\hline
\end{tabular}

SD — standard deviation; MIA — monoiodoacetate

\section{Statistical analysis}

To analyse the morphometric results and the degree of severity we used the Kruskal Wallis test and the Mann-Whitney $U$ test. To analyse inter-observer agreement for the degree of severity we used Cohen's kappa. The data were expressed as mean \pm standard deviation (SD). SPSS statistical software version 22.0 (IBM) was used with significance level of $5 \%$. GraphPad Prism 6.01 was used for all the graphs.

\section{RESULTS}

Morphometric changes in the mandibular condyle At 15 days post-induction the mean values for the height and transverse diameter of the condyle were slightly larger in both experimental groups than in the control group. At 30 days, the mean value for the anteroposterior diameter of the condyle was smaller in the experimental groups than in the control group. At 45 days, the increase in the mean values was more evident for all the variables in the MIA group than the control group; however, none of the measurements mentioned above presented statistically significant differences (Table 2).

\section{Morphometric changes in the joint disc}

At 15 and 30 days, the mean values for the anterior zone, posterior zone, height of the disc were slightly greater in the experimental groups than in the control group, but with no statistical significance. At 45 days the group with OA induced by MIA presented significantly higher mean values than the control group in the anterior zone ( $p \leq 0.001)$, posterior zone $(p=0.004)$ and disc height $(p=0.005)$ (Table 3).

\section{Morphometric changes in the articular tubercle}

At 15 days evolution of OA, the depth of the articular tubercle in the MIA experimental group was significantly larger than in the control and papain groups ( $p=0.046$ ) (Table 4 ). At 30 and 45 days the mean anteroposterior diameter and the depth of the articular tubercle were slightly greater in the MIA experimental group than in the control group, but with no statistically significant differences (Table 4).

\section{Histological changes in the mandibular condyle (induction by MIA)}

At 15 days a diminution was found in the thickness of the layers which compose the joint surface of the mandibular condyle, the joint capsule was very thin, almost non-existent, and the chondrocytes in the deep layers of the cartilage had become disoriented and formed isolated groups. At 30 days deformation was observed of the condyle surface, 
Table 3. Mean values found for the joint disc, comparison between the control group and the experimental groups (MIA and papain) against time $(15,30$ and 45 days $)$

\begin{tabular}{lcccc}
\hline Groups & Anterior zone & Posterior zone & Height \\
Mean (SD) & Mean (SD) & $0.69(0.04)$ & $3.97(0.36)$ \\
\hline Control group & MIA & $0.64(0.06)$ & $0.88(0.13)$ & $5.61(0.76)$ \\
15 days & $0.80(0.11)$ & $0.87(0.24)$ & $4.63(1.08)$ \\
& Papain & $0.78(0.16)$ & 0.276 & 0.077 \\
30 days & P & 0.190 & $0.89(0.19)$ & $4.81(0.34)$ \\
& MIA & $0.74(0.13)$ & $0.88(0.10)$ & $4.79(0.44)$ \\
45 days & Papain & $0.82(0.15)$ & 0.053 & 0.054 \\
& P & 0.113 & $1.05(0.11)$ & $5.46(0.88)$ \\
& MIA & $0.98(0.11)$ & $0.92(0.10)$ & $4.85(0.35)$ \\
\end{tabular}

SD — standard deviation; MIA — monoiodoacetate

Table 4. Mean values found for the depth of the articular tubercle, comparison between the control group and the experimental groups (MIA and papain) against time (15, 30 and 45 days)

\begin{tabular}{lcccc}
\hline Time & Groups & \multicolumn{1}{c}{ Depth } & & Anteroposterior diameter \\
\cline { 3 - 3 } & & Mean (SD) & & Mean (SD) \\
\hline Control group & & $1.64(0.33)$ & & $2.92(0.18)$ \\
15 days & MIA & $2.34(0.48)$ & & $3.05(0.49)$ \\
& Papain & $1.50(0.48)$ & & $2.49(0.20)$ \\
& P & 0.046 & & 0.108 \\
30 days & MIA & $2.15(0.63)$ & & $3.15(0.25)$ \\
& Papain & $2.15(0.28)$ & & $3.00(0.27)$ \\
& $P$ & 0.203 & & 0.602 \\
45 days & MIA & $1.83(0.27)$ & $3.01(0.36)$ \\
& Papain & $1.68(0.15)$ & $2.83(0.11)$ \\
& $P$ & 0.764 & 0.681 \\
\hline
\end{tabular}

SD — standard deviation; MIA — monoiodoacetate

which lost homogeneity and became irregular. The joint capsule was scarce and small superficial fibrillations were observed. The amount of extracellular matrix increased in the middle layers, while in the deepest layer a disorganised proliferation of chondrocytes was observed. At 45 days articular damage was evident: irregularity was observed in the condyle surface, the superficial layers were non-existent due to delamination of the articular cartilage. Cracks were observed in the extracellular matrix, extending to the mid zone of the cartilage and generating superficial clefts. Chondrocytes were scarce and had lost their morphology and cell membrane; some empty patches were even observed (Fig. 2).

\section{Histological changes in the mandibular condyle (induction by papain)}

At 15 days, the joint surface of the condyle was seen to be irregular; there was a slight increase in the extracellular matrix of the superficial layers of cartilage. At 30 days of evolution, the joint capsule was still easily identifiable, there was considerable increase in the extracellular matrix, the chondrocytes were disorganised in the middle layer and there was a proliferation of chondrocytes in the deep layer. At 45 days the joint surface was observed to be irregular, the joint capsule was thin, the chondrocytes of the middle layer were organised in isolated groups, with extracellular matrix predominating, no cracks were observed. The joint space between the condyle and the disc was considerably reduced (Fig. 2).

\section{Histological changes in the joint disc}

At 15 days the joint disc still conserved its normal configuration; however, small tears were observed on the surface. At 30 days the peripheral tears remained and a smaller number of chondrocytes was observed; the external borders presented irregularities but the disc still conserved its morphology. In the TMJ with OA induced by MIA we observed that in addition to 

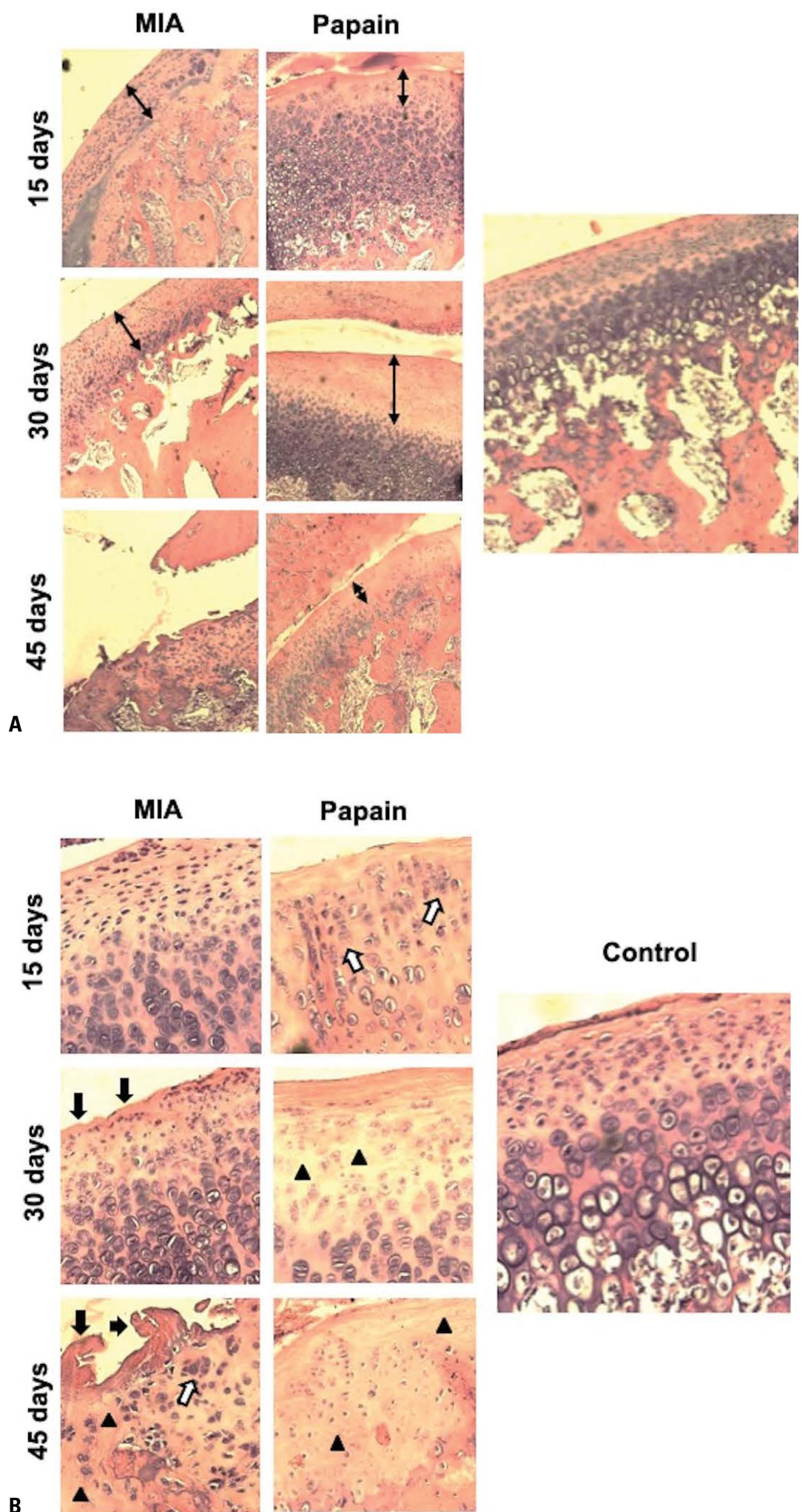

Figure 2. Sagittal section of temporomandibular joints. Histological changes in the condyles of the experimental groups at 15,30 and 45 days after induction of osteoarthritis (OA) by monoiodoacetate (MIA) and papain; A. Magnification 10×. Changes in the thickness of the joint surface (double-headed arrows); progressive diminution is evident in the MIA group, after 45 days the superficial layers have disappeared. In the papain group, the different layers of the joint surface are maintained, although with diminished thickness; B. Magnification 40×. Lesions typical of the evolution of $\mathrm{OA}$ are observed in both experimental groups: irregularity and deformation of the joint surface (black arrows), disorganised grouping of chondrocytes (white arrows), loss of chondrocytes and increase of cartilaginous matrix (arrowheads). 


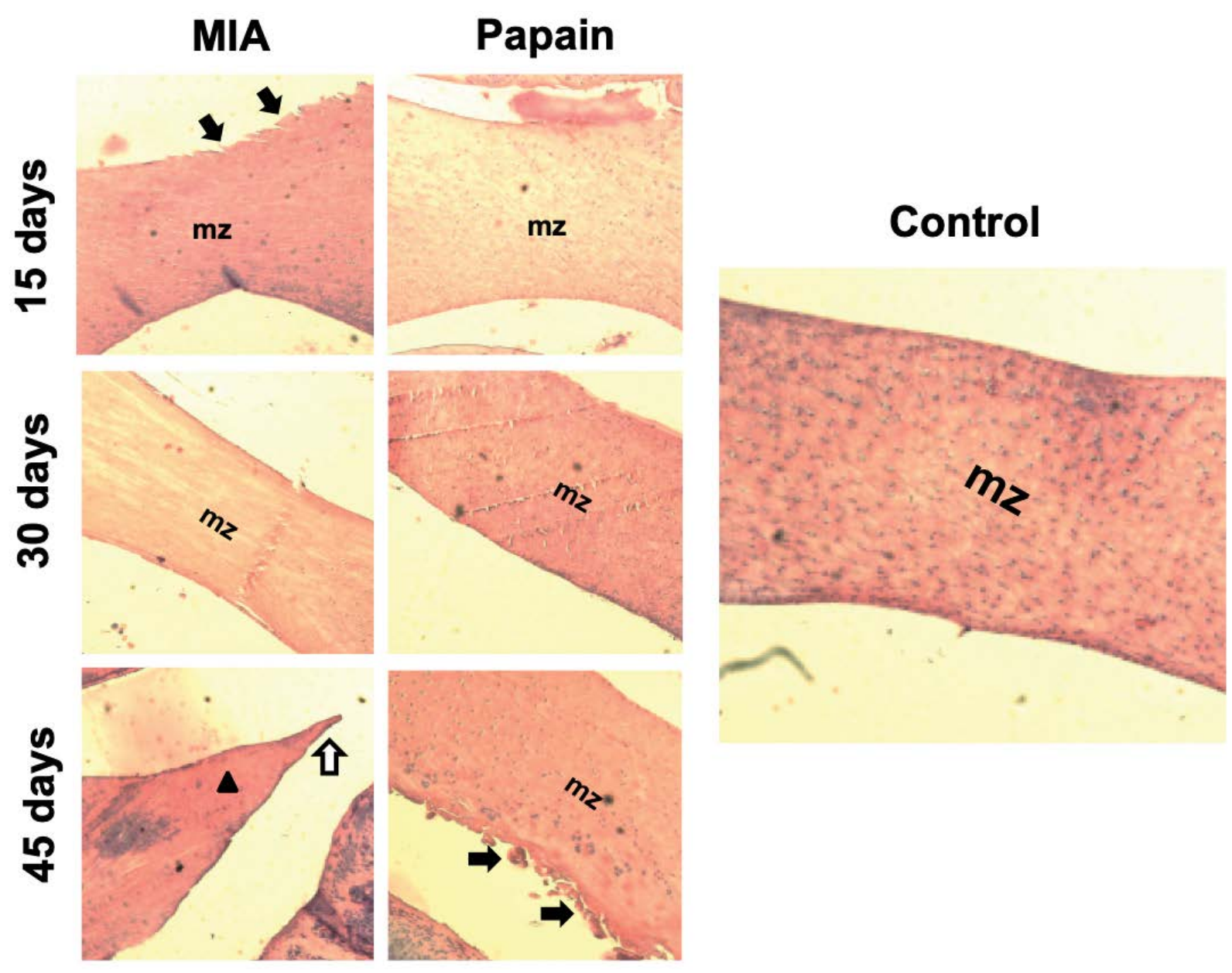

Figure 3. Sagittal section of temporomandibular joints, magnification $10 \times$. Shows histological changes in the joint discs of the monoiodoacetate (MIA) and papain experimental groups at 15,30 and 45 days after induction of osteoarthritis. The mid zone of the joint disc is observed (mz) with evidence of tears on the periphery (black arrows), loss of chondrocytes (arrowhead) and perforation of the joint disc (white arrow).

the changes to the condyle, the disc was perforated in the mid zone and chondrocytes were scarce on the edges (Fig. 3). In the TMJ with OA induced by papain we observed that the disc showed signs of tears, however chondrocytes could still be seen in its composition (Fig. 3).

\section{Analysis of the degree of severity}

The inter-observer agreement for the degrees of severity of the OA was moderate (kappa $=0.610$, $p<0.000$ ). The histological changes found in both experimental groups affected mainly the joint surface of the mandibular condyle (Table 5) and the joint disc (Table 6). OA with DS 2.5 can be observed after 15 days of induction by MIA. The maximum DS was recorded after 45 days induction by MIA.

\section{DISCUSSION}

Pre-clinical studies are important because they allow us to evaluate and describe the pathogenesis of a disease $[9,12]$, and also to carry out tests to analyse the effectiveness of new treatments, and possible adverse events related with these [23]. The rabbit is a suitable model for studying OA because of the structural and functional similarity existing between the human and the rabbit TMJ $[7,12,15]$.

Osteoarthritis can be induced in the TMJ of an animal model by the application of chemical inductors by arthrocentesis [4, 7] or surgically [22]. Chemical reproduction of $\mathrm{OA}$ by arthrocentesis presents advantages over surgical induction, since it is possible to control the concentration of the inductor, and therefore the progression and gravity of the lesion [7]. 
Table 5. Degree of severity (DS) of osteoarthritis found on the joint surface of the mandibular condyle of rabbit temporomandibular joints with induced osteoarthritis

\begin{tabular}{|c|c|c|c|c|c|c|}
\hline \multirow[t]{2}{*}{ Inductor } & \multicolumn{2}{|l|}{15 days } & \multicolumn{2}{|l|}{30 days } & \multicolumn{2}{|l|}{45 days } \\
\hline & Histological analysis & DS & Histological analysis & DS & Histological analysis & DS \\
\hline Monoiodoacetate & $\begin{array}{c}\text { Superficial and } \\
\text { deep fibrillation } \\
\text { Changes in the matrix } \\
\text { Scarce chondrocytes } \\
\text { located in the deep layer, } \\
\text { presenting very thin, } \\
\text { calcified disc, } \\
\text { with Haversian joint bone }\end{array}$ & 2 & $\begin{array}{l}\text { Deep fibrillation } \\
\text { Proliferation of chondro- } \\
\text { cytes, some hypertrophic, } \\
\text { with partial loss of } \\
\text { chondron orientation }\end{array}$ & 2 & $\begin{array}{l}\text { Presence of simple fissures } \\
\text { Delamination } \\
\text { of surface layer } \\
\text { Changes in N structure } \\
\text { Marked chondrocyte death } \\
\text { Chondrocytes grouped } \\
\text { in superficial layers }\end{array}$ & 4 \\
\hline Papain & $\begin{array}{l}\text { Marked chondrocyte death } \\
\text { Some hypertrophic } \\
\text { chondrocytes } \\
\text { Deep fibrillation } \\
\text { Chondrocytes in } \\
\text { conglomerates with loss of } \\
\text { chondron orientation }\end{array}$ & 2 & $\begin{array}{l}\text { Superficial fibrillation, } \\
\text { discontinuous surface } \\
\text { Numerous chondrocytes in } \\
\text { groups, initial formation of } \\
\text { chondrons } \\
\text { Some hypertrophic } \\
\text { chondrocytes }\end{array}$ & 2 & $\begin{array}{l}\text { Joint surface discontinuous, } \\
\text { with moderate fibrosis } \\
\text { Moderate alteration of } \\
\text { the cartilage } \\
\text { Significant diminution of } \\
\text { chondrocytes } \\
\text { Chondrocytes } \\
\text { conglomerated } \\
\text { to form chondrons } \\
\text { Hypertrophic chondrocytes } \\
\text { Haversian joint bone }\end{array}$ & 2 \\
\hline
\end{tabular}

Table 6. Histological changes found in the joint disc of rabbit temporomandibular joints with induced osteoarthritis

\begin{tabular}{lccc}
\hline Inductor & \multicolumn{1}{c}{$\mathbf{1 5}$ days } & $\mathbf{3 0}$ days & $\mathbf{4 5}$ days \\
\hline Monoiodoacetate & $\begin{array}{c}\text { The disc still conserves its } \\
\text { normal configuration, however } \\
\text { small tears are observed on } \\
\text { the surface }\end{array}$ & $\begin{array}{c}\text { At this time the disc still has } \\
\text { peripheral tears and a smaller } \\
\text { number of chondrocytes is } \\
\text { observed }\end{array}$ & $\begin{array}{c}\text { The mid zone of the disc is } \\
\text { perforated and chondrocytes } \\
\text { are scarce } \\
\text { at the edges }\end{array}$ \\
Papain & $\begin{array}{c}\text { The disc conserves its normal } \\
\text { architecture }\end{array}$ & $\begin{array}{c}\text { The joint disc shows signs of } \\
\text { irregularity around the external } \\
\text { border, but still conserves } \\
\text { its morphology }\end{array}$ & $\begin{array}{c}\text { The disc shows signs of tears, } \\
\text { however chondrocytes } \\
\text { can still be seen }\end{array}$ \\
in its composition
\end{tabular}

Furthermore the animals do not have to be subjected to surgery, resulting in lower risk and less suffering for the animal. Surgical induction also determines inflammation and joint damage produced by the trauma of an incision [2], which could affect the inflammation and installation of induced $O A$.

In the present study, two different chemical inductors were applied by arthrocentesis to induce OA. OA generates macroscopic changes in the mandibular condyle, characterised by erosion and irregularity of the joint surface and presence of osteophytes [4, 7]; this might explain the increase in the transverse diameter and height of the condyle found in the experimental groups in the present study. Furthermore, the thinning of the superficial cartilage layers agrees with the diminished values in the antero- posterior diameter of the condyle found in our study. In the present study, although the mean values for the mid zone of the disc were not significant, a considerable reduction occurred in the MIA group after 45 days due to the thinning, and in some cases disappearance, of this zone. A secondary cause of this situation is the damage to the condylar cartilage: the irregular, deformed condyle produces greater friction under movement, leading to evident changes which increase with the passage of time [2, 4, 25].

On the histological level, OA induction in the present study produced demonstrable changes in the joint surface of the condyle and disc. After 15 and 30 days post-induction by MIA and papain, the TMJs presented histological characteristics similar to 
OA of DS 2, with cracks in the extracellular matrix, small, deep superficial fissures, and hypertrophied chondrocytes. The hypertrophic reaction observed in the present study was also reported by Güler et al. [7] after 30 days of induction by MIA ( $3 \mathrm{mg} / \mathrm{mL})$, and by Cledes et al. [4] after 10 and 20 days of induction by MIA $(1.5 \mathrm{mg} / \mathrm{mL})$. One month after induction by MIA (3 mg/mL), Güler et al. [7] observed advanced arthritic lesions. Yang and Shi [26] also observed fibrillation and degeneration of cartilaginous matrix when they used papain to induce OA in rabbit TMJs. In the present study, the DS of OA increased with the passage of time. After 40 days, Cledes et al. [4] reported a large area of damage, with absence of cartilage and exposure of the subchondral bone in the joint cavity. At 45 days we observed cartilage erosion consistent with DS 4, according to Pritzker et al. [19], with delamination of the superficial layer, loss of chondrocytes and cartilaginous matrix, fissures reaching the mid zone, absence of the mid zone of the joint disc and peripheral tears. Artuzi et al. [2] also observed signs of erosion with loss of cartilaginous matrix after 60 days of induction by MIA, corroborating the findings of the present study. Güler et al. [7] reported that after 6 weeks of induction, the condylar cartilage presented a reaction characterised by thickening of the joint capsule, interruption of the osteochondral interface by multiple invaginations in the subchondral bone and hypocellularity of the chondrocytes. Cledes et al. [4] reported that the DS of OA is related with the exposure time and the concentration of the inductor applied [6]. In the present study, both inductors determined signs of OA from 15 days after induction; however, the animals exposed to MIA for 45 days presented a greater degree of severity, showing that the type of inductor and the exposure time were related with the DS of OA.

Previous studies have shown that papain $(0.2 \mathrm{~mL}$ concentrated) can cause fibrillation, osteoblast activity and death of some chondrocytes as early as 5 days after OA induction in the knee of mice [10]. After 2 weeks, these authors observed osteophyte formation and total necrosis of the cartilage with only a few chondrocytes; clusters and fibrillation were observed less frequently. Fifteen days after OA induction with papain, our findings confirmed OA of DS 2, with superficial fibrillation, chondrocyte clusters and hypertrophy, deep fibrillation and marked chondrocyte death. In a study of mouse knees, Murat et al. [17] injected papain; 15 days after the last injection, they observed that the joint presented an irregular surface, fibrillation, oedema and hypocellularity. These authors reported a direct proportion between the degree of degeneration and the time of induction, with findings at 4 weeks more consistent with osteoarthritic alterations [17]. Havdrup and Telhag [10] observed osteophyte formation around the edges, subchondral osteoblast activity and chondrocyte necrosis. In our study we did not observe progression of the disease with the passage of time; even at 45 days after the last papain injection, the degree of severity remained the same as was observed at 15 days, compatible with the initial phase of the disease. That papain did not determine a DS greater than 2 even after 45 days of induction may be related with the fact that the action of this proteolytic enzyme affects principally the collagen matrix, reproducing the primary stages of OA [3].

In the present investigation, we observed that the joint disc suffered progressive histological alterations when MIA was used as the inductor. After 15 days the disc presented normal configuration, but with small tears on the surface; at 30 days small peripheral ruptures could be seen and significant chondrocyte diminution, and 45 days after induction the disc was perforated. Cledes et al. [4] also observed perforation of the joint disc, with exposure of the bone in the joint cavity 40 days after induction by MIA. Induction by papain determined less significant changes; even 45 days after induction, the disc retained its morphology with few signs of tears. The severity and progression of the changes to the mandibular condyle and the joint disc were more expressive in the TMJs induced with MIA than in those induced with papain. Although the TMJs induced with papain presented signs compatible with $\mathrm{OA}$, the signs were indicative of an initial stage of the disease. Future studies could investigate the use of higher concentrations in order to determine whether papain is in fact able to produce a higher degree of severity, or only initial signs of OA. TMJs induced by MIA $(3 \mathrm{mg} / \mathrm{mL})$ showed a higher degree of severity 45 days after induction ( $D S=4$ ), showing that this model can be used in studies to evaluate the effectiveness of OA treatments. 


\section{Limitations of the study}

One limitation of the present study was not analysing the OA for a longer period than 45 days, in order to check on the progression of the disease. However, we note that degenerative signs were observed from day 15 after induction; at 45 days after induction by MIA signs compatible with OA could already be observed and interventions could be carried out from that time.

\section{CONCLUSIONS}

Both inductors were effective in reproducing slight degenerative alterations in rabbit TMJs, compatible with OA, 15 days after induction. At 45 days after induction by MIA the degenerative effects intensified to reach a moderate degree of severity. Inducement by arthrocentesis was quick and effective for reproducing a model of OA, as well as being cheap and presenting little risk for the animals. It is a suitable model for experiments aimed at evaluating the effectiveness of OA treatments.

\section{Acknowledgements}

Supported by Universidad de La Frontera, Dirección de Investigación, Project DI16-0046.

\section{REFERENCES}

1. Alves N, Garay I, Deana N, et al. CBCT Analysis of Rabbit Temporomandibular Joints With Osteoarthrosis Induced by Monoiodoacetate and Papain. Int J Morphol. 2018; 36(2): 513-518, doi: 10.4067/s0717-95022018000200513.

2. Artuzi FE, Langie R, Abreu MC, et al. Rabbit model for osteoarthrosis of the temporomandibular joint as a basis for assessment of outcomes after intervention. Br J Oral Maxillofac Surg. 2016; 54(5): e33-e37, doi: 10.1016/j. bjoms.2016.01.022, indexed in Pubmed: 26872897.

3. Bentley G. Papain-induced degenerative arthritis of the hip in rabbits. J Bone Joint Surg Br. 1971; 53(2): 324-337, indexed in Pubmed: 5578227.

4. Cledes G, Felizardo R, Foucart JM, et al. Validation of a chemical osteoarthritis model in rabbit temporomandibular joint: a compliment to biomechanical models. Int J Oral Maxillofac Surg. 2006; 35(11): 1026-1033, doi: 10.1016/j. ijom.2006.05.003, indexed in Pubmed: 16829037.

5. Ferrazzo KL, Osório LB, Ferrazzo VA. CT Images of a Severe TMJ Osteoarthritis and Differential Diagnosis with Other Joint Disorders. Case Rep Dent. 2013; 2013: 242685, doi: 10.1155/2013/242685, indexed in Pubmed: 24381768.

6. Guingamp C, Gegout-Pottie P, Philippe L, et al. Mono-iodoacetate-induced experimental osteoarthritis: a dose-response study of loss of mobility, morphology, and biochemistry. Arthritis Rheum. 1997; 40(9): 1670-1679, doi: 10.1002/art.1780400917, indexed in Pubmed: 9324022.
7. Güler N, Kürkçü M, Duygu G, et al. Sodium iodoacetate induced osteoarthrosis model in rabbit temporomandibular joint: CT and histological study (part I). Int J Oral Maxillofac Surg. 2011; 40(11): 1289-1295, doi: 10.1016/j. ijom.2011.07.908, indexed in Pubmed: 21885247.

8. Guzman RE, Evans MG, Bove S, et al. Mono-iodoacetate-induced histologic changes in subchondral bone and articular cartilage of rat femorotibial joints: an animal model of osteoarthritis. Toxicol Pathol. 2003; 31(6): 619-624, doi: 10.1080/01926230390241800, indexed in Pubmed: 14585729.

9. Harper RP, Kerins CA, Mclntosh JE, et al. Modulation of the inflammatory response in the rat TMJ with increasing doses of complete Freund's adjuvant. Osteoarthritis Cartilage. 2001; 9(7): 619-624, doi: 10.1053/joca.2001.0461, indexed in Pubmed: 11597174.

10. Havdrup T, Telhag H. Papain-induced changes in the knee joints of adult rabbits. Acta Orthop Scand. 1977; 48(2): 143-149, doi: 10.3109/17453677708985125, indexed in Pubmed: 868495.

11. Hunziker EB. Articular cartilage repair: basic science and clinical progress. A review of the current status and prospects. Osteoarthritis Cartilage. 2002; 10(6): 432-463, doi: 10.1053/joca.2002.0801, indexed in Pubmed: 12056848.

12. Kapila S, Lee C, Tavakkoli Jou MR, et al. Development and histologic characterizations of an animal model of antigen-induced arthritis of the juvenile rabbit temporomandibular joint. J Dent Res. 1995; 74(12): 1870-1879, doi: 10.1177/00220345950740121001, indexed in Pubmed: 8600183.

13. Kikuchi T, Sakuta T, Yamaguchi T. Intra-articular injection of collagenase induces experimental osteoarthritis in mature rabbits. Osteoarthritis Cartilage. 1998; 6(3): 177-186, doi: 10.1053/joca.1998.0110, indexed in Pubmed: 9682784.

14. Li X, Lang W, Ye H, et al. Tougu Xiaotong capsule inhibits the tidemark replication and cartilage degradation of papain-induced osteoarthritis by the regulation of chondrocyte autophagy. Int J Mol Med. 2013; 31(6): 1349-1356, doi: 10.3892/ijmm.2013.1341, indexed in Pubmed: 23589102.

15. Mills DK, Daniel JC, Herzog S, et al. An animal model for studying mechanisms in human temporomandibular joint disc derangement. J Oral Maxillofac Surg. 1994; 52(12): 1279-1292, doi: 10.1016/0278-2391(94)90051-5, indexed in Pubmed: 7965332.

16. Molinet M, Alves N. Anatomical considerations for applying the intra-articular injection technique in the temporomandibular joint of rabbits. Int J Clin Exp Med. 2019; (in press).

17. Murat N, Karadam B, Ozkal S, et al. [Quantification of papain-induced rat osteoarthritis in relation to time with the Mankin score]. Acta Orthop Traumatol Turc. 2007; 41(3): 233-237, indexed in Pubmed: 17876125.

18. O'Byrne EM, Blancuzzi V, Wilson DE, et al. Elevated substance $P$ and accelerated cartilage degradation in rabbit knees injected with interleukin-1 and tumor necrosis factor. Arthritis Rheum. 1990; 33(7): 1023-1028, doi: 10.1002/art.1780330715, indexed in Pubmed: 1695099.

19. Pritzker KPH, Gay S, Jimenez SA, et al. Osteoarthritis cartilage histopathology: grading and staging. Osteo- 
arthritis Cartilage. 2006; 14(1): 13-29, doi: 10.1016/j. joca.2005.07.014, indexed in Pubmed: 16242352.

20. Siebelt M, Groen HC, Koelewijn SJ, et al. Increased physical activity severely induces osteoarthritic changes in knee joints with papain induced sulfate-glycosaminoglycan depleted cartilage. Arthritis Res Ther. 2014; 16(1): R32, doi: 10.1186/ar4461, indexed in Pubmed: 24472689.

21. Swift J, Roszkowski M, Alton T, et al. Effect of intra-articular versus systemic anti-inflammatory drugs in a rabbit model of temporomandibular joint inflammation. J Oral Maxillofac Surg. 1998; 56(11): 1288-1295, doi: 10.1016/ s0278-2391(98)90611-5.

22. Tanaka E, Iwabe T, Dalla-Bona DA, et al. The effect of experimental cartilage damage and impairment and restoration of synovial lubrication on friction in the temporomandibular joint. J Orofac Pain. 2005; 19(4): 331-336, indexed in Pubmed: 16279485.
23. Vesterinen HM, Sena ES, Egan KJ, et al. Meta-analysis of data from animal studies: a practical guide. J Neurosci Methods. 2014; 221: 92-102, doi: 10.1016/j.jneumeth.2013.09.010, indexed in Pubmed: 24099992.

24. Wang XD, Kou XX, He DQ, et al. Progression of cartilage degradation, bone resorption and pain in rat temporomandibular joint osteoarthritis induced by injection of iodoacetate. PLoS One. 2012; 7(9): e45036, doi: 10.1371/ journal.pone.0045036, indexed in Pubmed: 22984604.

25. Xinmin Y, Jian Hu. Treatment of temporomandibular joint osteoarthritis with viscosupplementation and arthrocentesis on rabbit model. Oral Surg Oral Med Oral Pathol Oral Radiol Endod. 2005; 100(3): e35-e38, doi: 10.1016/j. tripleo.2004.12.025, indexed in Pubmed: 16122644.

26. Yang F, Shi ZA. study on papain induced osteoarthritis in rabbit temporomandibular joint. Hua Xi Kou Qiang Yi Xue Za Zhi. 2002; 20(5): 330-332. 